\title{
Fitoekstraksi Sianida pada Centrosema pubescens Benth yang Tumbuh di Limbah Tailing Terkontaminasi Sianida
}

\author{
Phytoextraction of Cyanide on Centrosema pubescens Benth Grown on Tailing Waste \\ Media Contaminated by Cyanide
}

\author{
Fauzia Syarif*, Nuril Hidayati, Titi Juhaeti
}

Pusat Penelitian Biologi LIPI - Cibinong Science Center Jl. Raya Bogor-Jakarta Kav. 44 Cibinong 16911 E-mail:criancht@yahoo.co.id*Penulis untuk korespondensi

\begin{abstract}
Contamination of mined soil and water affects not only to agriculture system but also food chains and epidemiological problems. As soil metal can not be biodegraded, remediation of soil heavy metal risks has been a difficult and expensive goal. Presently there are several different strategies available for the clean up and restoration of contaminated soils. One approach to minimize risks from some toxic pollutants is phytoextraction using hyperaccumulator plants, known as phytoremediation. In this research Centrosema pubescens was studied to examine its potency as hyperaccumulator against cyanide. Although cyanide is not categorized as heavy metal, its presence is considered as one of important toxic pollutants in the environments. Detoxification of cyanide $(\mathrm{CN})$ contaminated soils and waters with plants seems to be a feasible option. Centrosema pubescens which proven tolerant and dominant in the $\mathrm{CN}$ contaminated environment was used in this research. The plants were grown in tailing waste media added by $0,10,20$ and $30 \mathrm{ppm} C N$. Different $\mathrm{pH}$ levels were applied, i.e. \pm 6 and \pm 5 . The results showed that the plants were capable of growing under high level of $\mathrm{CN}$. The results indicated that Centrosema pubescens can be considered as high tolerance and potentially effective in accumulating $\mathrm{CN}$, i.e up to $3.564 \mathrm{ppm}$ in roots and up to $3.564 \mathrm{ppm}$ in shoot with concentration ratio (shoot/root) up to 1.13. The plants also indicated high tolerance by producing high biomass under high level of $\mathrm{CN}$, i.e up to $36.517 \mathrm{~g}$ (under $20 \mathrm{ppm} \mathrm{CN}$ ).
\end{abstract}

Key words: hyperaccumulator, phytoextraction, cyanide, Centrosema pubescens

Diterima: 23 April 2008, disetujui: 11 Desember 2008

\section{Pendahuluan}

Centrosema pubescens Benth merupakan salah satu jenis tumbuhan yang dapat beradaptasi terhadap lingkungan marginal seperti tanah limbah yang banyak terkontaminasi zat-zat beracun dan memiliki kualitas fisik, kimia maupun biologis sangat rendah. Dari penelitian sebelumnya Centrosema pubescens juga termasuk salah satu tumbuhan yang banyak dijumpai di sekitar limbah tailing dam di Cikotok Banten dengan nilai penting 19,73\% (Sambas et al., 2005). Selanjutnya hasil penelitian Juhaeti et al.,
(2006) menyatakan bahwa, Centrosema pubescens termasuk jenis tumbuhan fitoremediator $\mathrm{CN}$ yang berpotensi untuk dikembangkan karena dapat mengakumulasi sianida dengan kandungan yang tinggi yakni hingga 22,09 ppm. Disamping dapat mengakumulasi bahan beracun dalam jumlah tinggi, Centrosema pubescens juga dapat menghasilkan biomassa yang tinggi dibandingkan Calopogonium mucunoides dan Mikania cordata (Hidayati et al., 2006a). Penelitian ini bermaksud menguji lebih lanjut potensi tanaman ini sebagai tanaman akumulator $\mathrm{CN}$. 
Apabila tumbuhan dapat tumbuh baik, toleran terhadap lingkungan limbah yang tercemar, dan cepat tumbuh, serta mampu mengakumulasi substansi toksik dari dalam tanah dengan konsentrasi yang relatif besar maka diharapkan tumbuhan tersebut mampu bertindak sebagai akumulator bahan pencemar dan dapat digunakan sebagai mediator pembersih lingkungan yang tercemar atau fitoremediasi.

Sejumlah tumbuhan terbukti dapat beradaptasi terhadap lingkungan yang ekstrim seperti limbah pengolahan emas yang terkontaminasi logam berat dan sianida. Di antara tumbuhan ini banyak yang memiliki toleransi tinggi hingga mampu menyerap dan mengakumulasi logam kontaminan di dalam jaringannya. Potensi ini terbukti sangat penting dan berguna untuk dimanfaatkan sebagai mediator pembersih tanah dan perairan yang tercemar (Hidayati et al., 2006b).

Fitoekstraksi CN banyak dilakukan dengan menggunakan tanaman cyanogenik, yaitu spesies tanaman yang dapat mensintesis glukosida cyanogenic yang berfungsi dalam mendekomposisi $\mathrm{CN}$ bila jaringan tanaman terluka (Banks dan Mannering, 2006). Tanaman berpembuluh terbukti memiliki enzim yang dapat mendetoksifikasi $\mathrm{CN}$ dengan cara mengkonversinya ke asam amino asparagin (Larsen, 2005; Yu et al., 2005a; 2005b). Salah satu tanaman yang dikenal sebagai akumulator $\mathrm{CN}$ adalah Salix viminalis yang memiliki laju removal untuk daun dan akar masing-masing 9,5 dan $7 \mathrm{mg} \mathrm{kg}^{-1} \mathrm{~h}^{-1} \mathrm{CN}$. Adanya metabolisme $\mathrm{CN}$ dalam tanaman diindikasikan oleh hilangnya $\mathrm{CN}$ dari sistem media-tanaman hingga 50\%-80\% (Larsen, 2005).

Limbah tailing sebagaimana yang diketahui merupakan limbah yang tercemar $\mathrm{CN}$ baik dalam jumlah tinggi maupun rendah tetap akan membahayakan lingkungan disekitarnya. Untuk dapat mengurangi secara perlahan-lahan kandungan $\mathrm{CN}$ di lahan tersebut perlunya penelitian secara terintegrasi antara pemilihan jenis tanaman akumulator dan metode yang efektif, seperti penambahan pupuk, aplikasi kelat atau manipulasi $\mathrm{pH}$ media untuk membantu agar kontaminan lebih cepat terserap oleh tanaman akumulator.
Diantara faktor utama yang memiliki pengaruh langsung pada fitoekstraksi adalah spesies tanaman, $\mathrm{pH}$ media, kelat dan ketersediaan logam dalam media. Perlakuan $\mathrm{pH}$ media memiliki pengaruh besar terhadap fitoekstraksi karena $\mathrm{pH}$ berhubungan dengan kelarutan logam berat dan pembentukan kelat di dalam tanah. Selanjutnya $\mathrm{pH}$ juga menentukan kapasitas simpan tanah untuk logam berat konsentrasi ion-ion dalam larutan tanah. Perilaku dari unsur-unsur beracun dalam tanah sangat dipengaruhi oleh $\mathrm{pH}$. Seperti ketersediaan seng (Zn) yang menjadi rendah bila $\mathrm{pH}$ tanah lebih dari 7,0 karena unsur ini hanya terlarut pada kondisi masam. Sementara Aluminium (Al) meningkat daya larutnya pada kondisi masam (Salt, 2000).

Beberapa penelitian membuktikan bahwa manipulasi $\mathrm{pH}$ dan kesuburan tanah dapat meningkatkan akumulasi $\mathrm{Zn}, \mathrm{Ni}$, dan $\mathrm{Cd}$ pada tanaman (Brown et al., 1995). Kandungan (konsentrasi $\mathrm{x}$ total berat kering biomasa) $\mathrm{Zn}$ dan $\mathrm{Cd}$ pada tanaman yang diberi pupuk organik meningkat $3-10$ kali dibanding kontrol (Baker et al., 1994; Chaney et al., 1995). Setiap unsur logam memiliki respon yang berbeda terhadap perlakuan $\mathrm{pH}$ maupun pupuk (Chaney et al., 1998b).

Penelitian ini bertujuan mempelajari kemampuan akumulasi $\mathrm{CN}$ pada Centrosema pubescens yang ditanam pada media dengan konsentrasi $\mathrm{CN}$ dan tingkat $\mathrm{pH}$ yang berbeda untuk tujuan fitoremediasi lahan dan perairan terkontaminan $\mathrm{CN}$.

\section{Metode Penelitian}

Penelitian dilakukan di rumah kaca Bidang Botani, Puslit Biologi-LIPI di komplek Cibinong Science Center, Bogor. Penelitian ini menggunakan tanaman Centrosema pubescens dikenal dengan nama sentro. Benih sentro disemai dalam pot plastik berukuran tinggi 17 $\mathrm{cm}$, diameter atas $24 \mathrm{~cm}$ dan diameter bawah $18 \mathrm{~cm}$ sebanyak 20 biji. Setelah sentro berumur satu minggu dilakukan seleksi tanaman, hanya sepuluh yang diambil untuk penelitian. Media tanam berupa limbah tailing dam berasal dari PT ANTAM Cikotok Banten, dicampur dengan pupuk kandang dengan perbandingan 2:1. 
Penelitian terdiri dari 2 tahap perlakuan yakni tingkat konsentrasi pemberian $\mathrm{CN}$ dan perlakuan manipulasi $\mathrm{pH}$.

Perlakuan I: Penambahan $\mathrm{CN}$ ke media tanam terdiri dari 4 level yakni tanpa $\mathrm{CN}$ (kontrol), 10 ppm CN, 20 ppm CN, 30 ppm CN. Sumber CN diperoleh dari KCN.

Perlakuan II: 2 jenis $\mathrm{pH}$ media tanam, yakni pH 6-6,5 (netral) dan pH 5.0-5,2 (asam). Untuk menurunkan $\mathrm{pH}$ dengan menambahkan $20 \mathrm{ml}$ asam sitrat $1 \mathrm{~N}$ ke media tanam sesuai perlakuan. Setelah satu bulan umur tanaman dilakukan penambahan $\mathrm{CN}$ dan perlakuan $\mathrm{pH}$ ke media tanam sesuai perlakuan. Penelitian dirancang secara Acak Kelompok dalam faktorial dengan 7 ulangan. Parameter yang diamati: 1) Umur 1 bulan setelah pemberian $\mathrm{CN}$ ke media tanam, dilakukan panen I: penimbangan berat basah dan berat kering tajuk dan akar tumbuhan dan analisis $\mathrm{CN}$ dari masing-masing tajuk dan akar tumbuhan. 2) Umur 2 bulan setelah pemberian $\mathrm{CN}$ ke media tanam, dilakukan panen ke II: penimbangan berat basah dan berat kering tajuk dan akar tumbuhan, dihitung jumlah bintil akar dan diukur diameter bintil, analisis $\mathrm{CN}$ dari masingmasing tajuk dan akar tumbuhan, analisis $\mathrm{CN}$ media tanam dari masing-masing perlakuan.

Analisis $\mathrm{CN}$ dilakukan secara spektrofotometri di Balai Besar Penelitian dan Pengembangan Pascapanen Pertanian, Laboratorium Pengujian, Cimanggu Bogor Kandungan CN awal media tanam 1,188 ppm dan kandungan $\mathrm{CN}$ awal Centrosema pubescens $0,584 \mathrm{ppm}$.

\section{Hasil dan Pembahasan}

\section{Pertumbuhan tanaman}

Centrosema pubescens mampu tumbuh di tanah tailing yang ditambahkan CN sampai kosentrasi $30 \mathrm{ppm}$. Pertumbuhan Centrosema pubescens di media ber $\mathrm{pH} 5-5.2$ cenderung lebih baik dari pada di media dengan $\mathrm{pH} 6-$ 6.5 , pertumbuhan dicerminkan dalam bentuk berat basah tanaman yang terdiri dari tajuk dan akar (Tabel 1).

Data berat basah tajuk pada panen I menunjukkan tanaman yang diberi perlakuan CN 20 ppm (32.650 g) menghasilkan produksi biomasa tajuk paling tinggi, diikuti oleh perlakuan $10 \mathrm{ppm}(29.350 \mathrm{~g})$. Kedua tingkat produksi ini berbeda nyata bila dibandingkan dengan berat tajuk pada perlakuan CN 30 ppm dan kontrol (tanpa penambahan $\mathrm{CN}$ ). Hal ini mengindikasikan bahwa pada panen I ini (satu bulan setelah perlakuan $\mathrm{CN}$ ), tanaman masih belum banyak terpengaruh oleh $\mathrm{CN}$ atau dapat dikatakan bahwa tanaman masih toleran terhadap CN hinggá tingkat konsentrasi 20 ppm. Sementara data berat basah akar menunjukkan bahwa produksi akar pada semua perlakuan tidak berbeda nyata, walaupun secara riil produksi berat basah paling tinggi terjadi pada perlakuan CN 10 ppm (Tabel 1).

Tabel 1. Rata-rata Berat Basah Tajuk (BBT), Berat Basah Akar (BBA), Jumlah Bintil, Diameter Bintil Centrosema pubescens dengan Berbagai Perlakuan Tingkat Konsentrasi CN dan pH, Panen I dan II.

\begin{tabular}{lcccccc}
\hline \hline \multirow{2}{*}{ Perlakuan } & \multicolumn{1}{c}{ Panen I (1 Bulan Setelah Perlakuan) } & \multicolumn{5}{c}{ Panen II (2 Bulan Setelah Perlakuan) } \\
\cline { 2 - 6 } & BBT & BBA & BBT & BBA & \multicolumn{1}{c}{$\boldsymbol{\Sigma}$ Bintil } & \multicolumn{1}{c}{$\boldsymbol{\varnothing}$ Bintil } \\
\hline \hline Konsentrasi CN & & & & & & \\
$0 \mathrm{ppm}$ & $20.833 \mathrm{~b}$ & $2.933 \mathrm{a}$ & $36.59 \mathrm{~b}$ & $8.05 \mathrm{a}$ & $39 \mathrm{a}$ & $3.11 \mathrm{a}$ \\
$10 \mathrm{ppm}$ & $29.350 \mathrm{a}$ & $4.100 \mathrm{a}$ & $43.01 \mathrm{a}$ & $6.34 \mathrm{a}$ & $10.25 \mathrm{~b}$ & $3.22 \mathrm{a}$ \\
$20 \mathrm{ppm}$ & $32.650 \mathrm{a}$ & $3.867 \mathrm{a}$ & $34.74 \mathrm{~b}$ & $6.56 \mathrm{a}$ & $26.75 \mathrm{ab}$ & $2.98 \mathrm{a}$ \\
$30 \mathrm{ppm}$ & $24.060 \mathrm{~b}$ & $3.440 \mathrm{a}$ & $38.93 \mathrm{ab}$ & $4.41 \mathrm{a}$ & $11.43 \mathrm{~b}$ & $3.12 \mathrm{a}$ \\
\hline $\mathrm{pH}$ & & & & & & \\
Netral & $26.275 \mathrm{a}$ & $3.183 \mathrm{a}$ & $36.75 \mathrm{a}$ & $7.83 \mathrm{a}$ & $24.19 \mathrm{a}$ & $3.14 \mathrm{a}$ \\
Asam & $27.455 \mathrm{a}$ & $4.104 \mathrm{a}$ & $39.96 \mathrm{a}$ & $4.88 \mathrm{a}$ & $20.07 \mathrm{a}$ & $3.07 \mathrm{a}$ \\
\hline \hline
\end{tabular}

Keterangan: Angka yang diikuti huruf yang sama pada kolom dan baris yang sama menunjukkan tidak berbeda nyata pada taraf 5\% dengan uji Duncan. 
Data hasil panen II memperlihatkan peningkatan berat basah tajuk pada semua perlakuan $\mathrm{CN}$ dan kontrol dibandingkan panen I. Pada perlakuan $\mathrm{CN} 10 \mathrm{ppm}$, meningkat dari 29,35 g (panen I) menjadi 43,01 g (panen II), nilai ini berbeda nyata dibandingkan dengan perlakuan lainnya. Produksi tajuk pada panen II paling tinggi terjadi pada perlakuan $\mathrm{CN} 10$ ppm, berbeda dengan panen I yang terjadi pada perlakuan CN 20 ppm (Tabel 1). Walaupun termasuk normal bila dengan bertambahnya umur tanaman produksi biomasa meningkat, tetapi pada kasus keracunan $\mathrm{CN}$ atau logam berat biasanya terjadi sebaliknya, yaitu tanaman akan menunjukkan gejala keracunan dan diikuti kematian, kecuali dua hal yaitu apabila tanaman cukup toleran sehingga dengan tingkat kontaminasi yang diberikan tanaman masih dapat tumbuh normal. Pada panen II didapati berat basah tajuk menurun dengan perlakuan konsentrasi $\mathrm{CN}$ tinggi, sedangkan pada panen I terjadi sebaliknya. Hal ini terjadi kemungkinan karena pada panen I efek keracunan $\mathrm{CN}$ baru mulai terjadi sehingga belum banyak berpengaruh terhadap pertumbuhan tanaman sedangkan pada panen II keracunan $\mathrm{CN}$ telah berpengaruh terhadap pertumbuhan tanaman.

Berat basah akar pada panen II mengalami penambahan cukup tinggi dibandingkan panen I. Penambahan ini mencapai empat kali pada kontrol dan dua kali pada perlakuan $20 \mathrm{ppm}$ CN. Berat basah akar pada semua perlakuan tidak beda nyata secara statistik, tetapi secara riil produksi tertinggi terjadi pada kontrol, berbeda dengan data panen I produksi tertinggi terjadi pada perlakuan CN 10 ppm (Tabel 1).

Perlakuan $\mathrm{pH} 5$ dan 6 terbukti secara statistik tidak berpengaruh nyata terhadap pertumbuhan tanaman, walaupun secara riil ada indikasi perbedaan produksi biomasa (tajuk dan akar). Pertumbuhan Centrosema pubescens pada $\mathrm{pH} 5$ cenderung lebih baik dari pada $\mathrm{pH} 6$ pada panen I dan II walaupun tidak berbeda nyata secara statistik.

Jumlah bintil berbeda nyata antara kontrol dan perlakuan CN. Jumlah bintil paling tinggi terjadi pada tanaman kontrol. Hal ini menunjukkan bahwa $\mathrm{CN}$ dalam media tanam menghambat pertumbuhan bintil akar.
Diameter bintil sesama perlakuan tidak beda nyata. Jumlah bintil akar pada kedua tingkat $\mathrm{pH}$ juga tidak beda nyata, walaupun ada kecenderungan lebih baik pada media $\mathrm{pH} 6$.

Pada panen I indeks akar/tajuk paling tinggi terjadi pada perlakuan $\mathrm{pH} 6$ dan $\mathrm{CN} 10$ ppm dan terendah pada CN 20 ppm. Pada $\mathrm{pH} 6$, pada tingkat konsentrasi $\mathrm{CN}$ yang lebih tinggi indeks akar/tajuk menurun. Pada pH 5 terjadi hal sebaliknya (Gambar 1).

Pada panen II indeks akar/tajuk pada perlakuan $\mathrm{CN}$ mengalami penurunan sampai perlakuan CN 20 ppm, dan meningkat pada perlakuan $30 \mathrm{CN}$ ppm. Hal ini menunjukkan bahwa pertumbuhan tajuk Centrosema pubescens lebih dipengaruhi oleh $\mathrm{CN}$ dibandingkan pertumbuhan akarnya (Gambar 2).

\section{Serapan CN}

Data serapan $\mathrm{CN}$ dari panen I menunjukkan bahwa akumulasi CN lebih tinggi pada tajuk tanaman yakni mencapai 3,564 ppm (pada $\mathrm{pH}$ 6, CN $10 \mathrm{ppm}$ ), diikuti perlakuan $\mathrm{pH}$ 5, CN 30 ppm sebesar 3,168 ppm. Pada pH 6, akumulasi $\mathrm{CN}$ pada tajuk meningkat hingga pada tingkat konsentrasi $\mathrm{CN} 10 \mathrm{ppm}$. Pada $\mathrm{pH}$ 5 akumulasi $\mathrm{CN}$ pada tajuk meningkat dengan meningkatnya konsentrasi $\mathrm{CN}$ hingga tingkat konsentrasi $30 \mathrm{ppm}$. Hal yang sama juga terjadi pada serapan $\mathrm{CN}$ pada akar. Pada $\mathrm{pH} 6$ akumulasi $\mathrm{CN}$ pada akar paling tinggi terjadi pada perlakuan CN 10 ppm, yakni 3,168 ppm. Sementara pada $\mathrm{pH} 5$ akumulasi $\mathrm{CN}$ pada akar meningkat hingga pada perlakuan CN 30 ppm (Tabel 2). Hal ini sesuai dengan hasil temuan Syarif et al., (2007) bahwa, Centrosema pubescens pada umur dan kondisi yang sama merupakan tumbuhan yang toleran terhadap CN dibandingkan Calopogonium mucumunoides dan Cajanus cajan, dan mampu mengakumulasi $\mathrm{CN}$ pada tajuknya hingga 3.29 $\mathrm{mg} / \mathrm{l}$. 


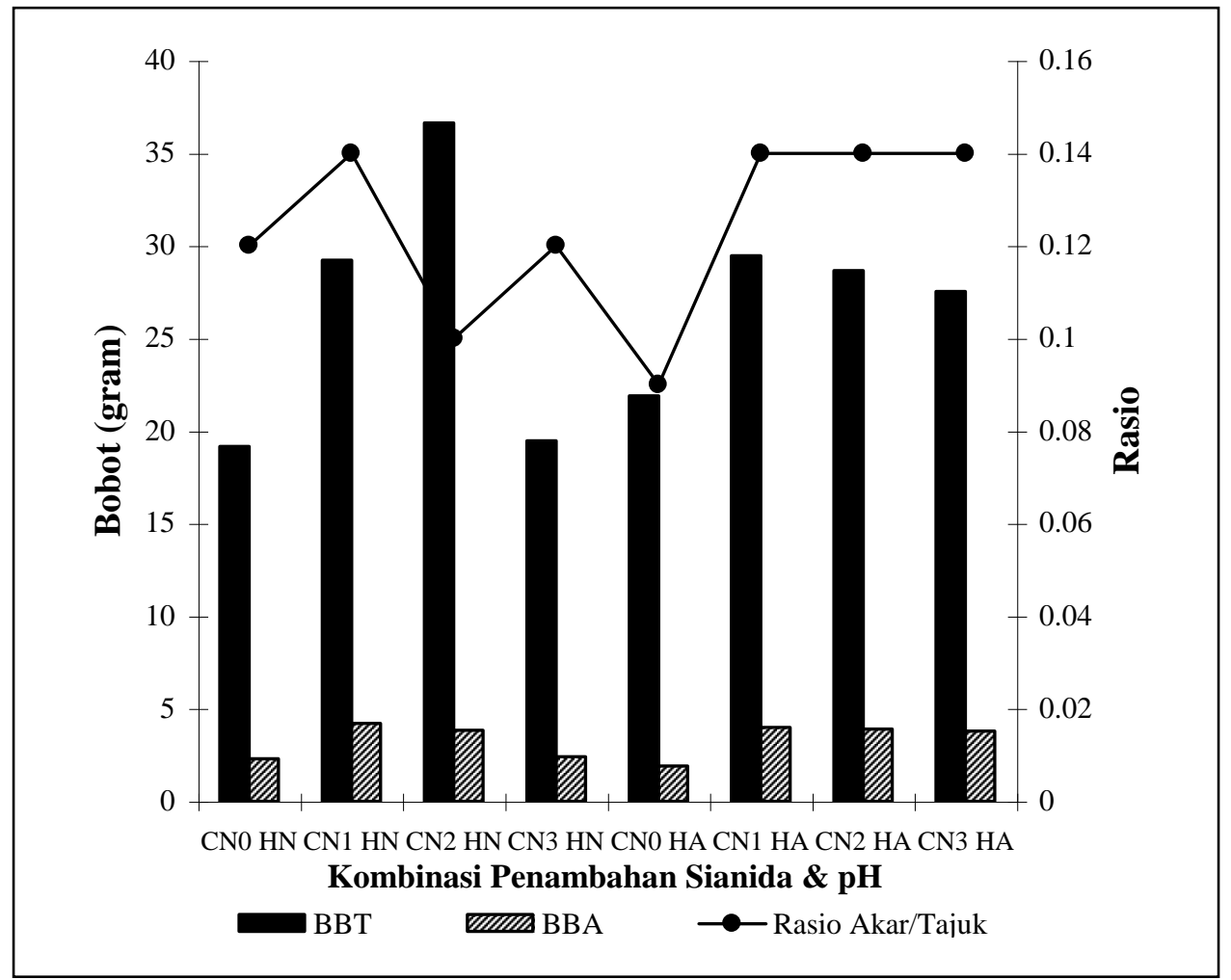

Gambar 1. Bobot Basah Tajuk (BBT), Berat Basah Akar (BBA), Indeks Akar/Tajuk Centrosema pubescens dengan Berbagai Perlakuan Tingkat Konsentrasi CN dan Jenis pH, Panen I.

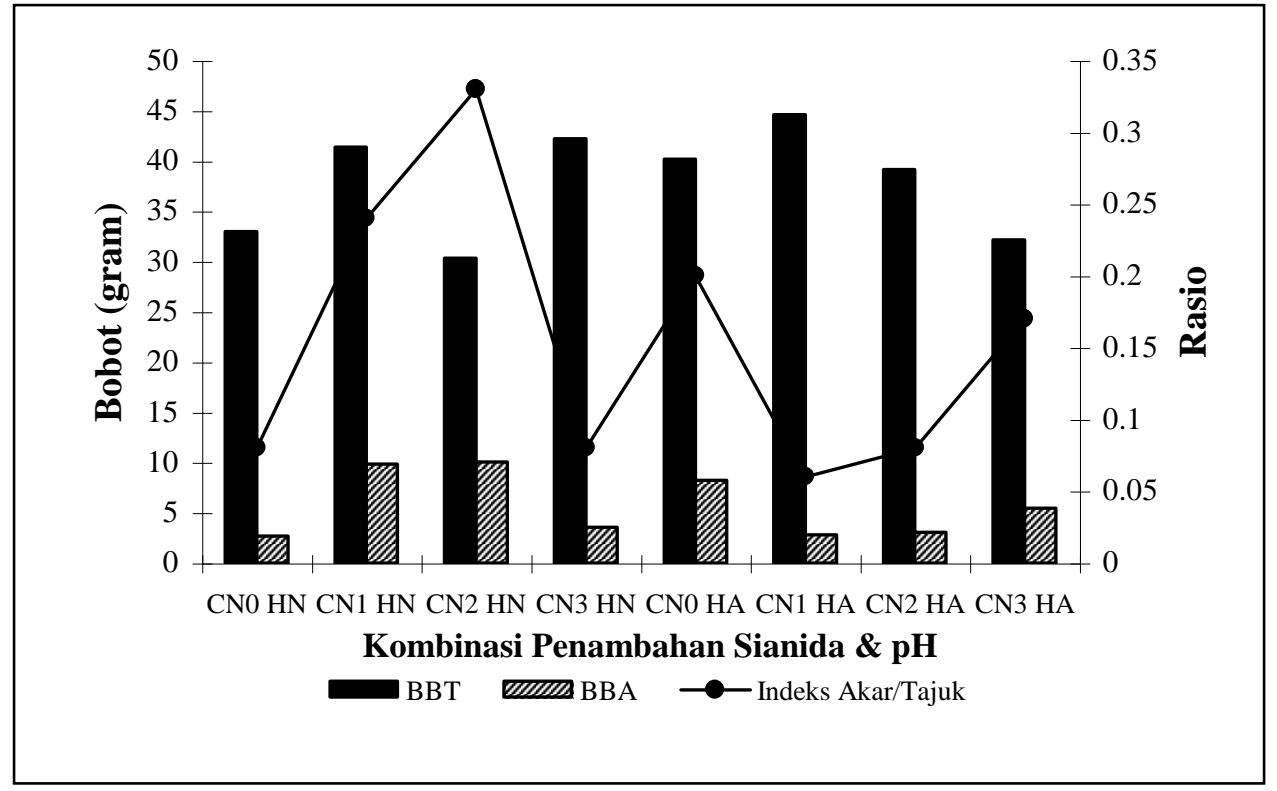

Gambar 2. Bobot Basah Tajuk (BBT), Berat Basah Akar (BBA), Indeks Akar/Tajuk Centrosema pubescens dengan Berbagai Perlakuan Tingkat Konsentrasi CN dan Jenis $\mathrm{pH}$, Panen II.

Keterangan: CN0: tanpa penambahan $\mathrm{CN}, \mathrm{CN} 1: 10$ ppm, CN2: 20 ppm, CN3: 30 ppm, HN: pH Netral, HA: pH Asam. 
Data dari panen II menunjukkan bahwa akumulasi CN total secara keseluruhan perlakuan lebih rendah dibandingkan panen I, yakni hingga $<0.01$. Pada perlakuan $\mathrm{CN} 10$ ppm dengan $\mathrm{pH} 6$ penurunannya mencapai sepuluh kali dibandingkan panen I. Pengurangan $\mathrm{CN}$ dalam tanaman ini sesuai dengan temuan bahwa di dalam tanaman terjadi metabolisme $\mathrm{CN}$ yang toksik menjadi asam amino yang tidak toksik (Larsen, 2005). Temuan tersebut menyatakan bahwa semua tanaman berpembuluh terbukti memiliki enzim yang dapat mendetoksifikasi $\mathrm{CN}$ dengan cara mengkonversinya ke asam amino asparagin (Larsen, 2005; Yu et al., 2005a; 2005b). Tanaman yang dikenal sebagai akumulator CN adalah Salix viminalis yang memiliki laju removal untuk daun dan akar masing-masing sebesar 9,5 dan $7 \mathrm{mg} \mathrm{kg}^{-1} \mathrm{~h}^{-1} \mathrm{CN}$. Adanya metabolisme $\mathrm{CN}$ dalam tanaman diindikasikan oleh hilangnya $\mathrm{CN}$ dari sistem media-tanaman 50\%-80\% (Larsen, 2005).

Total kandungan $\mathrm{CN}$ panen I di kedua media meningkat dibandingkan kandungan $\mathrm{CN}$ awal Centrosema pubescens yakni 0,584 ppm, pada panen II terjadi penurunan yang sangat banyak berkisar $2-20$ kali dan juga ada $<0.01$ ppm pada perlakuan $30 \mathrm{ppm} \mathrm{CN}$ menunjukkan serapan $\mathrm{CN}$ juga ditentukan dari umur tumbuhan, membuktikan bahwa serapan $\mathrm{CN}$ pada Centrosema pubescens lebih efektif satu bulan setelah perlakuan (umur tanaman dua bulan), akumulasi $\mathrm{CN}$ di tajuk lebih tinggi waktu umur dua bulan daripada umur tiga bulan. Hal yang sama juga terjadi di media $\mathrm{pH}$ asam, walaupun serapan $\mathrm{CN}$ di tajuk mengalami peningkatan tetapi total kosentrasi serapannya menurun dibandingkan pada panen I.

Rasio konsentrasi tajuk/akar di media $\mathrm{pH}$ netral pada panen I yang tertinggi pada kontrol yakni 1,67 diikuti perlakuan 10 ppm CN yakni 1,13. Tingginya rasio konsentrasi karena serapan $\mathrm{CN}$ di tajuk lebih tinggi dari pada resapan di akar. Membuktikan Centrosema pubescens respons terhadap akumulasi $\mathrm{CN}$ pada umur satu bulan setelah penambahan $\mathrm{CN}$ ke media tumbuh. Rasio konsentrasi tajuk/akar semakin kecil dengan semakin tingginya konsentrasi $\mathrm{CN}$ yang diberikan. Brown et al., (1995) melaporakan salah satu karakter tumbuhan akumulator apabila laju translokasi logam dari akar ke tajuk lebih tinggi dari pada akar.

Pada $\mathrm{pH} 5$ serapan $\mathrm{CN}$ tertinggi pada perlakuan 30 ppm CN yakni 3.168 ppm, memperlihatkan semakin tinggi konsentrasi CN yang diberikan maka semakin tinggi serapan $\mathrm{CN}$ di tajuk. Hal ini menunjukkan bahwa Centrosema pubescens memiliki karakter sebagai tumbuhan hiperakumulator untuk $\mathrm{CN}$.

Kandungan CN di media setelah panen II (umur 3 bulan) tidak bisa dideteksi sangat kecil sekali $(<0.01 \mathrm{ppm})$ untuk semua perlakuan kecuali pada pemberian $30 \mathrm{ppm} \mathrm{CN}$ di media $\mathrm{pH}$ asam yakni $0,396 \mathrm{ppm}$. Terjadi penurunan kandungan $\mathrm{CN}$ di media cukup banyak bila dibandingkan dengan waktu awal yakni 1,188 ppm dan media yang diberi perlakuan $\mathrm{CN} 10$, 20 dan $30 \mathrm{ppm}$. Temuan ini menunjukkan bahwa Centrosema pubescens cukup efektif dalam menurunkan kandungan pencemar $\mathrm{CN}$ karena terbukti setelah dua kali panen kandungan $\mathrm{CN}$ pada media tanam menurun secara signifikan hingga mencapai tingkat yang sangat rendah (tidak terdeteksi).

\section{Kesimpulan dan Saran}

\section{Kesimpulan}

Tanaman Centrosema pubescens mampu tumbuh dan memproduksi biomasa pada kondisi media terkontaminasi $\mathrm{CN}$ hingga tingkat konsentrasi $30 \mathrm{ppm}$. Hal ini ditunjukkan oleh pertumbuhan yang dicerminkan oleh produksi biomasa (tajuk dan akar) dan produksi bintil akar yang tidak berbeda nyata antara perlakuan dan kontrol. Disamping itu Centrosema pubescens juga menunjukkan kemampuan dalam mengakumulasi $\mathrm{CN}$ baik pada tajuk maupun pada akar yang cukup tinggi dengan rasio konsentrasi pada tajuk/akar lebih dari satu. Dimana kenyataan ini mengindikasikan bahwa tanaman ini memiliki karakteristik sebagai tanaman akumulator $\mathrm{CN}$.

\section{Saran}

Perlu dilakukan penelitian lebih lanjut mengenai jenis-jenis tumbuhan yang telah terbukti memiliki prospek dalam 
membersihkan pencemar dalam tanah dan air temasuk tumbuhan Centrosema pubescens.

\section{Ucapan Terima Kasih}

Terima kasih kami sampaikan kepada PT Aneka Tambang, Cikotok Kabupaten Lebak Propinsi Banten dan PT Aneka Tambang, Pongkor Kabupaten Bogor Jawa Barat yang telah memberi kami fasilitas sewaktu di lapangan.

\section{Daftar Pustaka}

Baker, A.J.M., Reeves, R.D. and Hajar, A.S.M. 1994. Heavy Metal Accumulation and Tolerance in British Populations of The Metallophyte Thlaspi caerulescens J. \& C. Presl (Brassicaceae). New Phytol 127: 61-68.

Banks, M.K. and Mannering, F. 2006. Phytoremediation of Cyanide Contaminated Soils. http://www. hsrc.org/mw-cyanide.html. 09/30/2006.

Brown, S.L., Chaney, R.L., Angle, J.S. and Baker, A.J.M. 1995. Zink and Cadmium Uptake by Hyperaccumulator Thiaspi Caerulescens Grown in Nutrient Solution. Soil Sci.Soc.Am.J 59:125-133.

Chaney, R.L., Brown, S.L., Li, Y.M., Angle, J.S., Homer, F. and Green, C. 1995. Potential Use of Metal Hyperaccumulators. Mining Environ Management 3 (3): 9-11.

Chaney, R.L., Li, Y.M., Angle, J.S., Baker, A.J.M., Reeves, R.D., Brown, S.L., Homer, F.A., Malik, M. and Chin, M. 1998b. Improving Metal Hyperaccumulators Wild Plants to Develop Commercial Phytoextraction System: Aproaches and Progress. In: Proc Symp Phytoremediation, Inc Conf Biochemistry of Trace Elements Berkeley, CA. In Press. 23-26 Juni 1997.

Hidayati, N., Syarif, F. dan Juhaeti, T. 2006a. Potensi Centrosema pubescens, Calopogonium mucunoides dan Mikania cordata dalam Membersihkan Logam Kontaminan pada Limbah Penambangan Emas. Biodeversitas. J. of Biological Diversity 7: 4-6.
Hidayati, N., Juhaeti, T. and Syarif, F. 2006b. Mercury and Cyanide Contamination in Aquatic Environments Around Two Gold Mine Areas and Possible Solution of Using Green Technology of Phytoremediation. International JSPS Seminar. Bogor.

Juhaeti, T., Syarif, F. dan Hidayati, N. 2006. Potensi Tumbuhan Liar Dari Lokasi Penampungan Limbah Tailing PT.ANTAM Cikotok Untuk Fitoremediasi Lahan Tercemar Sianida. J. Teknologi Lingkungan. Edisi khusus" Hari Lingkungan Pengembangan Sumberdaya Alam Badan Pengkajian Dan Penerapan Teknologi. 191-197.

Larsen, M. 2005. Plant Uptake of Cyanide. Ph.D. Thesis. Institute of Environment and Resources. Technical University of Denmark. 37p.

Salt, D.E. 2000. Phytoextraction: Present Aplications and Future Promise. In: Wise, D.L., Trantolo, D.J., Cichon, E.J., Inyang, H.I. and Stottmeister, U. Bioremediation of Cotaminated Soils Marcek Dekker Inc. New York Basell. Pp. 729-743.

Sambas, E.N., Juhaeti, T., Syarif, F., Hidayati, N. dan Komarudin, E. 2005. Komposisi Jenis Tumbuhan Bawah di Tailing Penambangan Emas Cikotok. Laporan Tehnik. Pusat Penelitian Biologi-LIPI.

Syarif, F., Hidayati, N. dan Juhaeti, T. 2007. Potensi Hipertoleransi Calopogonium mucunoides Desv, Centrosema pubescens Benth dan Cajanus cajan (L.) Millsp yang Tumbuh pada Limbah Penambnagan Emas Terkontaminasi Sianida dan Merkuri. J. Biologi Indonesia. IV (4): 239-247.

Yu, X., Zhou, P., Zhou, X. and Liu, Y. 2005a. Cyanide Removal by Chinese VegetationQuantification of The Michaelis-Menten Kinetics. Environ.Sci.Pollut.Res.Int. 12 (4): 221-226.

Yu, X., Trapp, S. and Zhou, P. 2005b. Phytotoxicity of Cyanide to Weeping Willow Trees. Sci. J.Com.http://dx.doi.org/10.1065/espr2005.02. 237.03/07/2006. 